that, in the brains of people with the neurodegenerative disorder, immune cells are unable to clear away the plaques that are hallmarks of the disease.

N. Engl. J. Med. 368, 107-116; 117-127 (2013)

\section{MICROBIOLOGY}

\section{Leprosy bacteria reprogram cells}

The bacterium that causes leprosy spreads through the body by reprogramming infected cells to become stemcell-like cells that can form other cell types.

Leprosy is caused by the bacterium Mycobacterium leprae, which infects Schwann cells that insulate nerve cells. When Anura Rambukkana at the University of Edinburgh, $\mathrm{UK}$, and his colleagues infected mouse Schwann cells with the bacterium, they found that the cells expressed genes typical of an earlier developmental stage. After they were injected into mouse muscle, these stem-celllike cells turned into muscle cells, and the bacteria spread to neighbouring muscle tissue. The stem-cell-like cells also transferred bacteria to immune cells called macrophages, which spread the infection further.

Understanding how $M$. leprae reprograms cells could inform treatment strategies, as well as provide tools for regenerative medicine, the authors say.

Cell 152, 51-67 (2013)

For a longer story on this research, see go.nature.com/fbkksy

\section{Compressed picture-taking}

Digital cameras take images as arrays of pixels that are compressed by algorithms into a smaller file. But a system designed by John Hunt and his colleagues at Duke University, Durham, North Carolina, can generate a compressed picture without the need for a postprocessing stage.
The device uses an approach that samples image data at random, but still includes enough information to generate a good-quality image. The authors used an aperture made of a strip of metamaterial - an artificial structure that interacts with light in ways not found in nature - that guides microwaves to a single-pixel sensor. The patterns in the material are 'transparent' to certain wavelengths, so the signal 'leaks' information as it moves down the strip, allowing for the random data sampling.

Using this system, the researchers created a video of a moving object's path in one dimension. The technology could one day be used in airport scanners, radar systems and infrared imaging, the authors say.

Science 339, 310-313 (2013)

\section{HYDROLOGY}

\section{Irrigation brings more rain}

Agricultural irrigation in the Central Valley of California doubles the amount of water vapour in the atmosphere, leading to increased rainfall throughout the southwestern United States.

James Famiglietti and Min-

Hui Lo of the University of California, Irvine, analysed the impact of irrigation on climate using a global climate model. They found that irrigation adds so much water to the region's hydrological cycle through evaporation and transpiration (whereby plants release water into the atmosphere) that summer precipitation is increased by $15 \%$. As a result, summer run-off is raised by $56 \%$ across the region and by $28 \%$ in the Colorado River Basin, which is a source of fresh water for southern California.

A better understanding of the impact of irrigation on regional climate and water availability can improve resource management, the authors say. org/10.1002/grl.50108 (2013)

COMMUNITY CHOICE

The most viewed papers in science

\title{
Cancer drugs from algae
}

\section{HIGHLY READ \\ on www.pnas.org in December}

Algae could be used to make complex, targeted cancer drugs, thanks to their photosynthetic organelles, the chloroplasts. Immunotoxins are drugs that combine a toxin with an antibody; the antibody targets the toxin to specific cells, such as cancer cells. However, the drugs have proved difficult and expensive to produce. Stephen Mayfield and his colleagues at the University of California, San Diego, reasoned that the green alga Chlamydomonas reinhardtii could be used to produce immunotoxins. The chloroplasts of this alga contain the machinery to properly fold complex proteins - such as antibodies - and can tolerate some toxins.

The team used the alga to produce an antibody to CD22 - a protein found on a type of immune cell called a B cell coupled to a bacterial toxin. The immunotoxin killed B cells in culture, and inhibited the growth of human B-cell tumours that had been implanted in mice.

Proc. Natl Acad. Sci. USA 110, E15-E22 (2013)

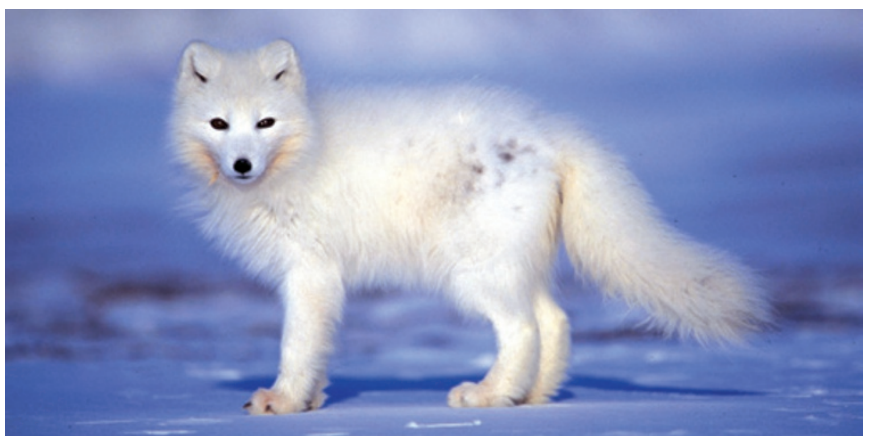

ECOLOGY

\section{Arctic rain brings animal pain}

Winter rain, an unusual event in the high north, drives animal numbers on a Norwegian Arctic island into decline, showing that extreme climate events can affect an entire community of vertebrates.

Brage Hansen at the Norwegian University of Science and Technology, Trondheim, and his team found that populations of Svalbard reindeer (Rangifer tarandus platyrhynchus), rock ptarmigan (Lagopus muta hyperborea) and sibling voles (Microtus levis) on the island of Spitsbergen crash during especially rainy winters - when the animals' food is coated in layers of ice. The extreme weather synchronizes fluctuations in the population numbers of these herbivores. This, in turn, causes numbers of the Arctic fox (Vulpes lagopus; pictured) - which preys on ptarmigans and voles, and feeds on reindeer carrion - to oscillate, but with a oneyear lag.

The overwintering vertebrate community could represent a bellwether for the influence of global warming on Arctic ecosystems, if climate change raises the prevalence of warmer and wetter winters.

Science 339, 313-315 (2013)

\section{- NATURE.COM}

For the latest research published by Naturevisit:

www.nature.com/latestresearch 